\title{
7-Nitroindazole and Methylene Blue, Inhibitors of Neuronal Nitric Oxide Synthase and NO-Stimulated Guanylate Cyclase, Block MK-801-Elicited Behaviors in Mice
}

\author{
Stephen I. Deutsch, M.D., Ph.D., Richard B. Rosse, M.D., Steven M. Paul, M.D., \\ Vincent Tomasino, M.D., Lee Koetzner, B.A., Cassandra B. Morn, B.A., \\ and John Mastropaolo, Ph.D.
}

We examined the abilities of 7-nitroindazole and methylene blue, inhibitors of the neuronal isoform of nitric oxide synthase (NOS) and nitric oxide-stimulated guanylate cyclase activity respectively, to attenuate explosive episodic jumping behavior(s) ("popping") elicited by MK-801 in mice. MK-801, like phencyclidine (PCP), is a high-affinity, noncompetitive antagonist of the $\mathrm{N}$-methyl-D-aspartate (NMDA) subtype of glutamate receptor. We have postulated that MK-801-elicited popping behavior in mice represents an animal model of schizophrenia, because popping behavior is markedly inhibited/antagonized by both typical and atypical antipsychotic drugs. In the present study, popping behavior induced by MK-801 was measured using an automated detection system that quantifies

KEY WORDS: 7-Nitroindazole; Methylene blue; MK-801; Phencyclidine; Antipsychotic; Popping behavior

In certain neurons, glutamate-stimulated $\mathrm{Ca}^{2+}$ conductance via the N-methyl-D-aspartate (NMDA) receptor-

From the Department of Veterans Affairs Medical Center (SID, RBR, VT, LK, CBM, JM), Psychiatry Service, Washington, DC; the Department of Psychiatry (SID, RBR), Georgetown University School of Medicine, Washington, DC; the Lilly Research Laboratories (SMP), Eli Lilly and Company, Indianapolis, Indiana; and the Departments of Psychiatry, Pharmacology, and Toxicology (SMP), Indiana Lniversity School of Medicine, Indianapolis, Indiana.

Address correspondence to: Stephen I. Deutsch, M.D., Ph.D., Department of Veterans Affairs Medical Center, Psychiatry Service, Room 3A154/116A, 50 Irving Street, N.W., Washington, D.C. 20422.

Received April 21, 1995; revised July 26, 1995; accepted July 28, 1995. vertical displacements on the testing platform.

7-Nitroindazole $(100 \mathrm{mg} / \mathrm{kg})$ and methylene blue (32 and $100 \mathrm{mg} / \mathrm{kg}$ ) significantly reduced the number and force of MK-801-elicited popping behavior. Mouse rotorod performance did not differ between animals receiving 7-nitroindazole, methylene blue, or their respective vehicles, suggesting that attenuation of MK-801-elicited popping behavior was not due to either sedation or ataxia caused by 7-nitroindazole or methylene blue. Our findings suggest that nitric oxide may, in part, mediate behaviors induced by NMDA receptor antagonists, like $M K-801$, and that inhibitors of NOS may have antipsychotic actions.

[Neuropsychopharmacology 15:37-43, 1996]

associated ion channel leads to the production of nitric oxide (NO), a freely diffusible gaseous intercellular messenger (Dawson et al. 1992; Moncada and Higgs 1993). Effects attributed to NMDA receptor stimulation may, in some instances, be mediated by NO production and the resultant cascade of intracellular biochemical events induced by NO. For example, NO increases cyclic GMP synthesis by activating the soluble heme-containing form of guanylate cyclase (Dawson et al. 1992; Moncada and Higgs 1993; Murad 1994). NO is one product of a reaction catalyzed by nitric oxide synthase (NOS) that utilizes arginine as its substrate. NOS activity is due to multiple isoenzymes, which are both constitutively active and inducible depending on the tissue 
and cell type (Snyder and Bredt 1992; Moore et al. 1993). The distribution of immunohistochemically positive NOS-containing neurons is similar to that of neurons stained with nitro-blue-tetrazolium (NBT) used for the detection of nicotinamide adenine dinucleotide diaphorase (NADPH) activity (Dawson et al. 1992). Although NOS/NADPHd-staining neurons comprise only $1 \%$ to $2 \%$ of all neurons in the brain (Dawson et al. 1992), their neuronal processes have extensive ramifications throughout the brain.

Commonly used preclinical screening methods for identifying antipsychotic compounds generally involve testing the ability of such compounds to antagonize dopamine-mediated rodent behaviors elicited by direct or indirectly acting dopaminergic mimetics (Ferris et al. 1982). A limitation of these preclinical tests is that they identify compounds whose primary pharmacologic action involves antagonism of dopamine-stimulated behaviors. Although such methods have proven effective in identifying many of the currently used typical antipsychotic medications, they may be ineffective in identifying atypical medications that produce few, if any, ex trapyramidal side effects (EPS) and appear to be more efficacious in treating the "deficit" symptoms of schizophrenia (see Meltzer 1991 for review).

Given the many similarities between phencyclidine (PCP)-induced behaviors in humans and schizophrenia (Javitt and Zukin 1991; Deutsch et al. 1989; Javitt 1987), several investigators have examined the ability of both typical and atypical drugs to antagonize PCP-induced behaviors in rodents (Deutsch and Hitri 1993; Schmidt 1991). In our laboratory, we have studied the behavioral effects of MK-801 ([ + ]-5-methyl-10,11-dihydro-5H-dibenzo [a,d] cyclohepten-5, 10-imine maleate; dizocilpine), an analogue of PCP that binds with high-affinity to the NMDA receptor complex, in mice (Foster and Wong 1987; Deutsch and Hitri 1993). MK-801 elicits hyperactivity, stereotypic behaviors, and an episodic explosive jumping behavior ("popping") in mice (Deutsch and Hitri 1993). Both typical and atypical antipsychotic medications have been reported to block MK-801-elicited behaviors in mice in a dose-dependent manner (Deutsch and Hitri 1993; Schmidt 1991).

In the current study, we examined whether 7-nitroindazole (7-NI) and methylene blue (MB), two drugs known to interfere with NO-mediated signal transduction (da Silva et al. 1994; Mayer 1993; Martin et al. 1985), would affect MK-801-elicited popping behavior in mice (Deutsch and Hitri 1993; Rosse et al. 1995). 7-NI has been shown to dose-dependently inhibit the neuronal isozyme of NOS, and to be centrally active when administered peripherally to rats (Babbedge et al. 1993; Moore et al. 1993). MB antagonizes the ability of NO to stimulate cyclic GMP production by binding to the heme moiety of the NO-sensitive soluble guanylate cyclase (Mayer et al. 1993; Martin et al. 1985); MB may also interfere with other steps along the NO "cascade" (Mayer et al. 1993). We anticipated that these compounds, whose actions effectively antagonize NOmediated signal transduction, would exacerbate behaviors elicited by MK-801. Unexpectedly, 7-NI and MB were shown to markedly reduce MK-801-elicited popping behavior(s). These data suggest that inhibitors of NO synthase or NO function may have antipsychotic activity.

\section{METHODS}

\section{Animals}

An outbred strain of male NIH Swiss Webster mice weighing approximately $25 \mathrm{~g}$ were obtained from the National Cancer Institute (Frederick, MD) and used in all experiments. Mice were housed in hanging wire mesh cages in groups of five and maintained on a 12hour light/12-hour dark cycle with free access to food and water. Animals were weighed individually prior to drug injection and automated assessment of platform motor behaviors and rotorod performance.

\section{Drugs}

MK-801 (Research Biochemicals International; Natick, MA) was dissolved in 0.9\% saline. 7-NI (Biomol, Plymouth Meeting, PA) was suspended by ultrasonic agitation in 2-hydroxypropyl-b-cyclodextrin (Research Biochemical International; Natick, MA). MB was obtained from Sigma Chemical Co. (St. Louis, MO) and dissolved in distilled water. All drugs were injected intraperitoneally (IP) in a volume of $0.01 \mathrm{ml} / \mathrm{g}$ of body weight.

\section{Computerized Assessment of MK-801-Elicited Popping}

An automated system for measuring explosive episodic popping behaviors was used to study the effects of 7-NI and MB on MK-801-induced popping behavior. This method is based on the detection and measurement of small vertical displacements of a platform induced by motor movements (Rosse et al. 1995). These vertical displacements are detected and converted to electrical signals (S72-25 Type A Transducer Coupler and S76-01 [Modified] Contour Following Integrator; Coulbourn Instruments, Inc., Allentown, PA) and transformed into a digital signal (L25-12 A/D Converter; Coulbourn Instruments, Inc., Allentown, PA). The digitized data are stored and later analyzed on an IBM compatible computer. In the present study, a popping count was identified as a vertical displacement of the platform of more than $150 \%$ of body weight. The computer also determines the strength of individual pops in gram equivalents of force exerted against the platform. Reverbera- 
tions or "aftershock" movements of the platform, which occur after vigorous movements or jumps, were removed automatically in a manner similar to that used in measuring startle responses in laboratory animals (Coulbourn Instruments, Inc., Allentown PA).

The recording of MK-801-elicited popping behavior was divided into two phases: a 5-minute baseline period after pretreatment with either 7 -NI (40 minutes prior), MB (10 minutes prior), or appropriate vehicle. The baseline period was then followed by administration of MK-801 and 30 minutes of recording. All mice were individually weighed and put into separate cages that were placed on the pressure platforms. The platforms were then calibrated so that the force on each platform including the cage and weight of the animal was measured as " 0 "; all forces from animal movements resulting in downward displacements of the platform were measured.

\section{Rotorod Assessment}

To evaluate possible sedative/ataxic properties of 7-NI and MB we used a rotorod (Biological Research Apparatus, Model 7600 , Comerio Varese, Italy) rotating at a constant speed of $16 \mathrm{rpm}$. Rotorod assessment was divided into two phases: a baseline period of 5 minutes, during which the animals were replaced on the rotating rod in the event of failure to maintain balance. Subsequent to this, a 5-minute testing period began after the administration of either 7-NI (40 minutes), MB (10 minutes), or appropriate vehicle.

\section{RESULTS}

All analyses were performed on an IBM-compatible computer using Statistica (StatSoft, Inc., Tulsa, OK). In experiments examining the interaction of 7-NI and MK801, the results of a two-way ANOVA revealed two significant main effects and a significant interaction. As predicted, MK-801 significantly induced popping in a dose-dependent manner $(F=9.2$, df $=3,88, p=.00002)$. Additionally, a significant main effect for $7-\mathrm{NI}(F=19.4$, $d f=1,88, p=.00002)$ indicates that $7-\mathrm{NI}(100 \mathrm{mg} / \mathrm{kg})$ significantly attenuated MK-801 induced popping. The average peak force of these pops was also subjected to a two-way ANOVA, revealing two significant main effects (7-NI pretreatment, $F=16.5$, df $=1,88, p=.0001$; MK-801 dose, $F=14.9$, $d f=3,88, p=.000001$; interaction not significant) (see Figure 1).

$\mathrm{MB}$ at $10 \mathrm{mg} / \mathrm{kg}$ was found to reduce only marginally the average number of pops (two-way ANOVA; MB pretreatment, $F=3.2$, df $=1,88, p=.08$; MK-801 dose, $F=10.9$, df $=3,88, p=.000004$; interaction was not significant). The average peak force of pops was not significantly influenced by $\mathrm{MB}$ at $10 \mathrm{mg} / \mathrm{kg}$ (two-way
ANOVA; MB pretreatment, $F=0.2$, df $=1,87, p=.6$; MK-801 dose, $F=25.4, d f=3,88, p<.000001$; the interaction was not significant) (see Figure 2). However, at a dose of $32 \mathrm{mg} / \mathrm{kg}, \mathrm{MB}$ was found to reduce the average number of pops significantly (two-way ANOVA; MB pretreatment, $F=6.9$, $d f=1,88, p=.01$; MK-801 dose, $F=9.5, d f=3,88, p=.00002$; interaction not significant). The average peak force of pops was also significantly influenced by $\mathrm{MB}$ at the $32 \mathrm{mg} / \mathrm{kg}$ dose (twoway ANOVA; MB pretreatment, $F=52.2, d f=1,88, p<$ .0000001 ; $M K-801$ dose, $F=12.96$, df $=3,88, p<.000001$; the interaction was not significant) (see Figure 3 ). At the higher dose (100 $\mathrm{mg} / \mathrm{kg}$ ), MB was found to have a significant effect on both the average number of pops (twoway ANOVA, factor $1, \mathrm{MB}$ pretreatment, $F=20$, df = $1,88, p=.00002$; factor 2 , MK-801 dose, $F=4.9$, $d f=$ $3,88, p=.003$; interaction significant, $F=4.3, d f=3,88$, $p=.0076)$ and the average peak force of these pops (two-way ANOVA; factor $1, \mathrm{MB}$ pretreatment, $F=38, d f=$ $1,88, p=.000001$; factor 2, MK-801 dose, $F=8.5, d f=$ $3,88, p=.00005$; interaction significant, $F=4.2, d f=3,88$, $p=.007)$ (See Figure 4).

$7-\mathrm{NI}(100 \mathrm{mg} / \mathrm{kg})$ and $\mathrm{MB}(10,32,100 \mathrm{mg} / \mathrm{kg})$ failed to alter rotorod performance (one-way ANOVA, 7-NI, $F=2.61, d f=1,1 ; \mathrm{MB}, F=0.46, d f=1,3)$ compared to their respective vehicles (see Figure 5).

\section{DISCUSSION}

The recognition that NO production can be an important "downstream" consequence of glutamate-induced elevations of intraneuronal $\mathrm{Ca}^{2+}$ has prompted considerable interest in the possible development of NO interventions for therapeutic purposes (Bredt and Snyder 1992; Dawson et al. 1992). Excessive stimulation of NMDA receptors has been shown to mediate many of the neuropathologic consequences of hypoxic, hypoglycemic, or traumatic insults to brain (Iversen et al. 1989). NMDA antagonists are under consideration for development as neuroprotective and antiseizure agents.

There is also a growing interest in the role of the NO pathway in the idiopathic psychotic disorder of schizophrenia. Recently, Karson and colleagues (1991) have reported differences in the number of NOS-containing neurons in the brainstem of schizophrenic patients compared to appropriately matched controls. In this study, patients with schizophrenia were reported to have increased numbers of NAPDHd-stained neurons in the pedunculopontine (PPN) nucleus (Karson et al. 1991). These cholinergic PPN neurons send excitatory signals to thalamus and midbrain, structures critical to sensory gating processes (Karson et al. 1991). Problems with sensory gating at the level of the thalamus have been proposed as important in the pathophysiology of schizophrenia (Andreason et al. 1994). In another recent 


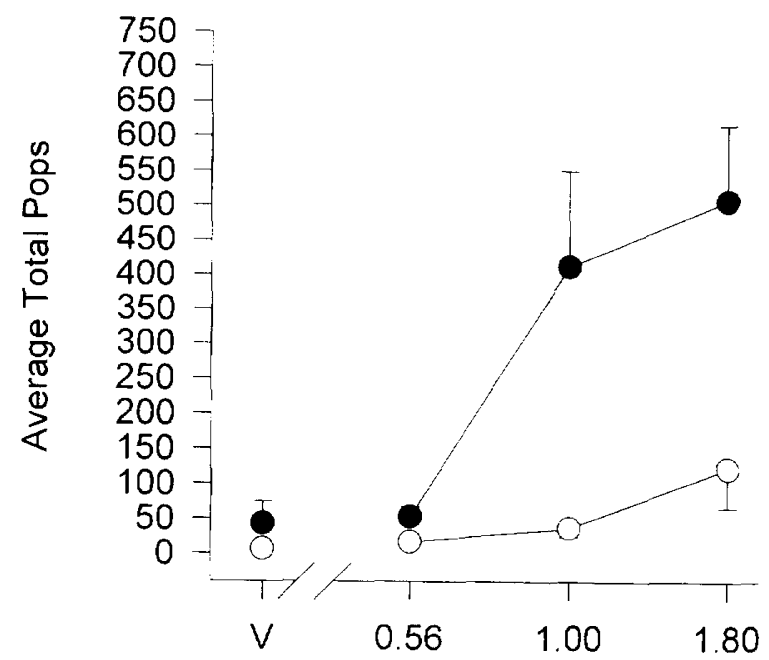

A

MK-801 $(\mathrm{mg} / \mathrm{kg})$

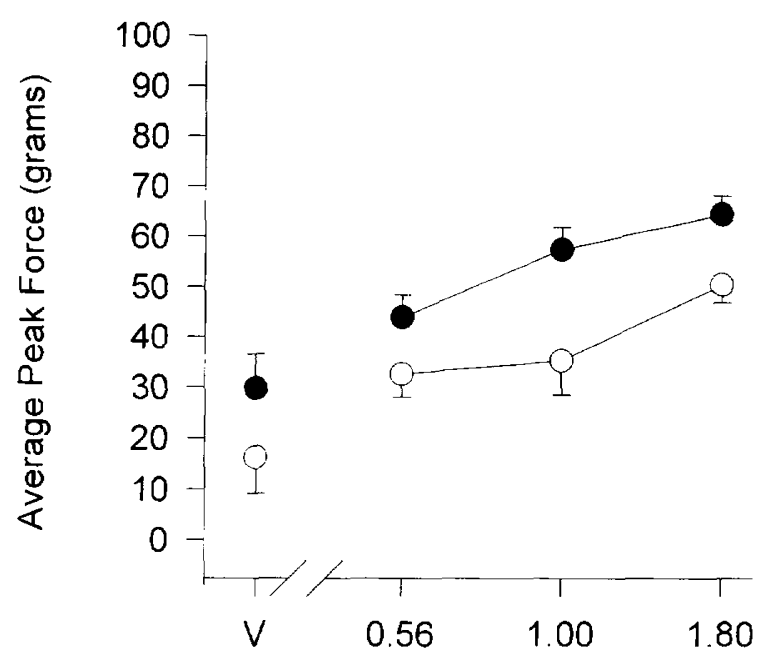

B

MK-801 (mg/kg)

Figure 1. (A) Mean ( \pm SEM) number of pops during a testing session for groups of mice ( $n=12 /$ group) injected with $0.9 \%$ saline (the MK-801 vehicle, points above V) and either $100 \mathrm{mg} / \mathrm{kg}$ of 7-nitroindazole (open circles) or its vehicle (cyclodextrin) (solid circles). (B) The details are identical to $\mathbf{A}$, with the exception that the data are depicting the force of pops.

study, an increase in the number of NADPHd-stained neurons in the deep layers of the white matter of the dorsolateral prefrontal cortex (DLPFC) were reported in schizophrenic patients (Akbarian et al. 1993a). Patients with schizophrenia also had greater numbers of NADPHd-stained neurons in the parahippocampal and lateral temporal lobe white matter (Akbarian et al. 1993b). Interestingly, it has been reported that NO may enhance both dopamine and serotonin release in certain brain regions (Lorrain and Hull 1993). The possible rela- tionship between NO synthesis and the release of dopamine and serotonin is interesting in light of evidence that atypical antipsychotic drugs such as clozapine have both antidopaminergic and antiserotonergic properties (Meltzer et al. 1989). Additionally, NO, through a cGMP pathway, has been shown to stimulate the phosphorylation of DARPP-32, resulting in the amplification of dopamine neural transmission through certain dopamine receptors (Tsuo et al. 1993). Finally, reports of elevated platelet NOS activity and plasma cit-

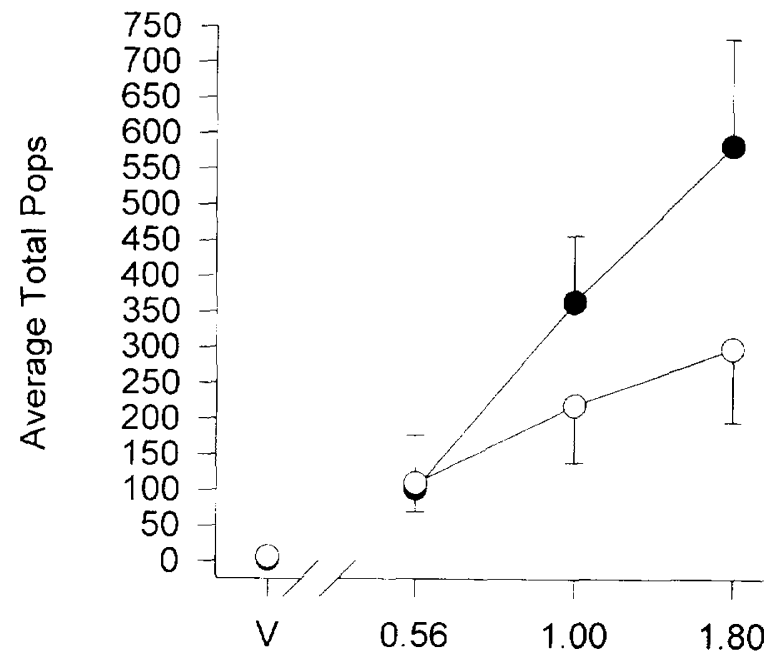

A

MK-801 (mg/kg)

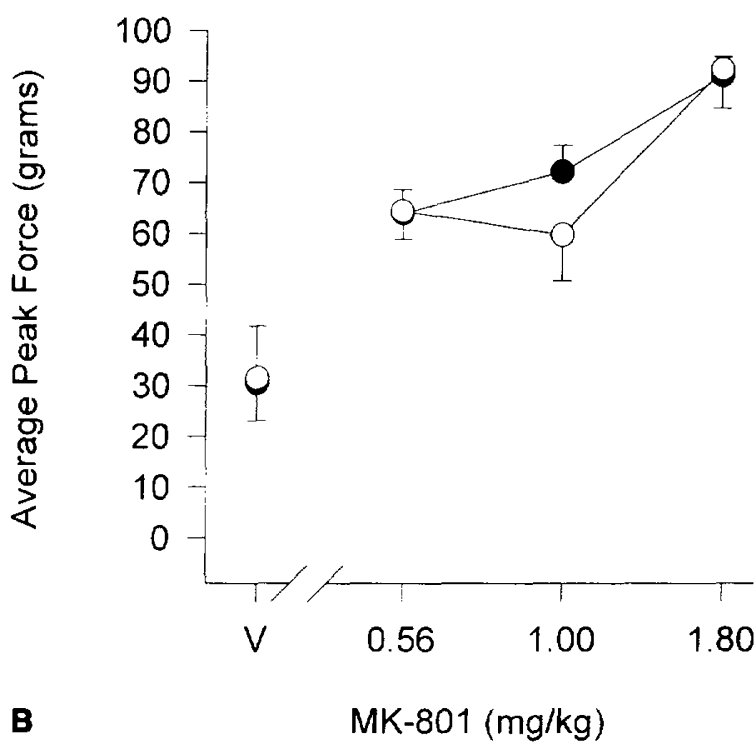

Figure 2. All details are the same as in Figure 1, with the exception that data are presented for $10 \mathrm{mg} / \mathrm{kg}$ of methylene blue (open circles), whose vehicle was distilled water (solid circles). Also note that the group size for mice injected with $0.9 \%$ saline and distilled water (closed circle above point $\mathrm{V}$ ) was 11 in (A). 

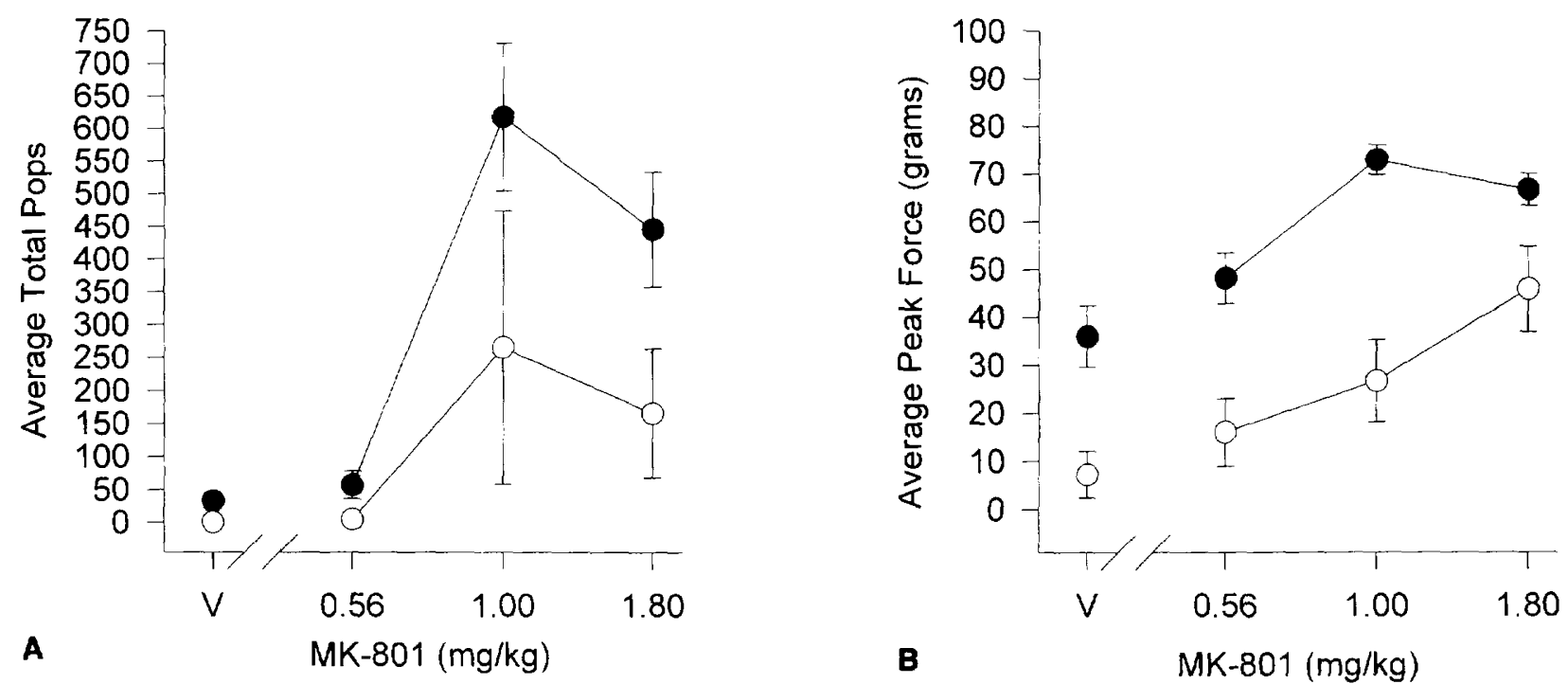

Figure 3. All details are the same as in Figure 1, with the exception that data are presented for $32 \mathrm{mg} / \mathrm{kg}$ of methylene blue (open circles), whose vehicle was distilled water (closed circles).

rulline/arginine ratios in patients with schizophrenia have been interpreted as possibly representing heightened brain NOS activity in schizophrenia (Das et al. 1995; Khan et al. 1995). Hence, the ability to attenuate the downstream consequences of the NO cascade might be of therapeutic benefit in patients with schizophrenia.

The ability of PCP to precipitate a schizophreniform psychosis coupled with its well-described pharmacologic action as an uncompetitive antagonist of NMDA receptors has led to a "glutamatergic deficiency hypothesis" of the pathophysiology of schizophrenia (Javitt and Zukin 1991; Deutsch et al. 1989; Javitt 1987). In light of the evidence that 7-NI and MB antagonize NMDA re- ceptor-mediated activation of the $\mathrm{NO}$ cascade (i.e., $\mathrm{NO}$ synthesis and NO-induced cyclic GMP production, respectively), one would anticipate that the intensity of MK-801-elicited popping behaviors should be enhanced by their administration. Contrary to this prediction, in the current report, 7-NI and MB markedly inhibited MK-801-induced popping behaviors at doses that were by themselves devoid of significant sedative/ataxic effects. There is no clear explanation as to why an inhibitor of either NOS or NO function would antagonize MK-801-induced motor behaviors in mice that would be compatible with the glutamatergic deficiency hypothesis of schizophrenia. Conceivably, interference with
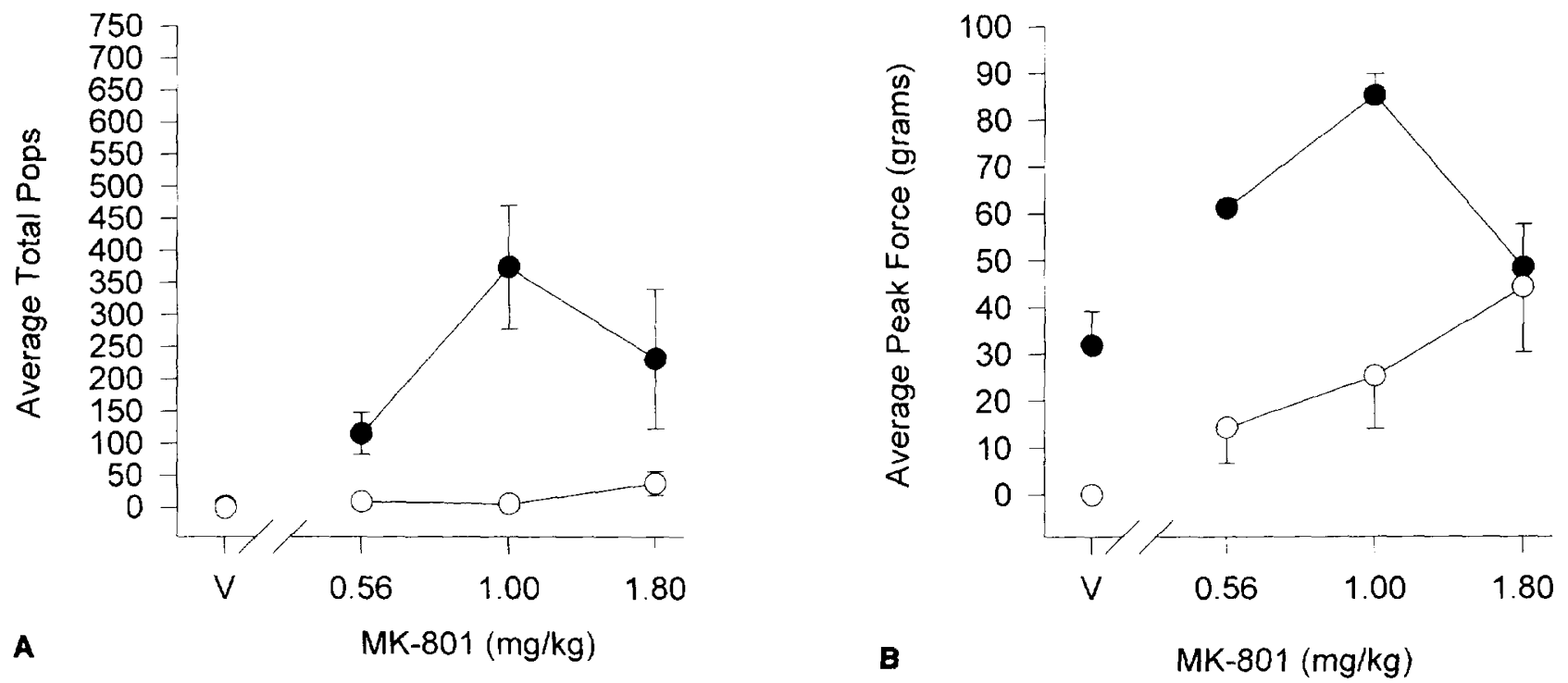

Figure 4. All details are the same as in Figure 1, with the exception that data are presented for $100 \mathrm{mg} / \mathrm{kg}$ of methylene blue (open circles), whose vehicle (solid circles) was distilled water. 


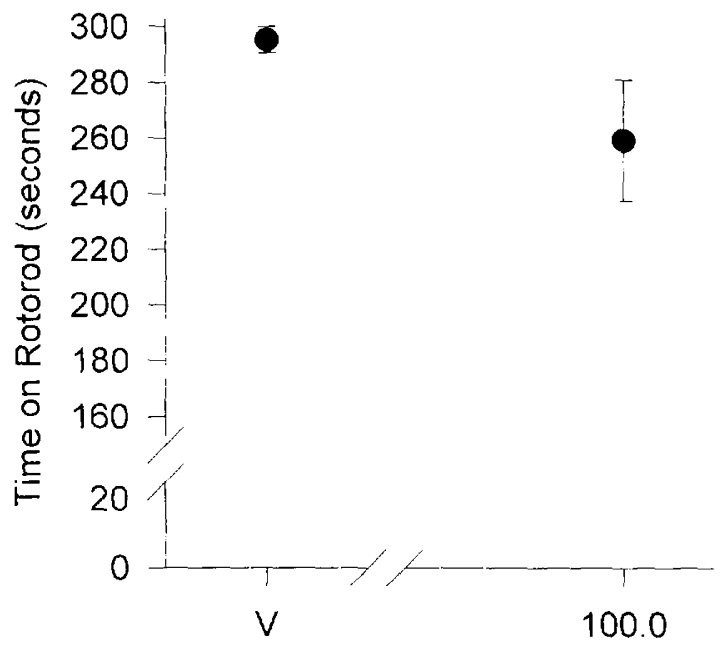

A

7-Nitroindazole $(\mathrm{mg} / \mathrm{kg})$

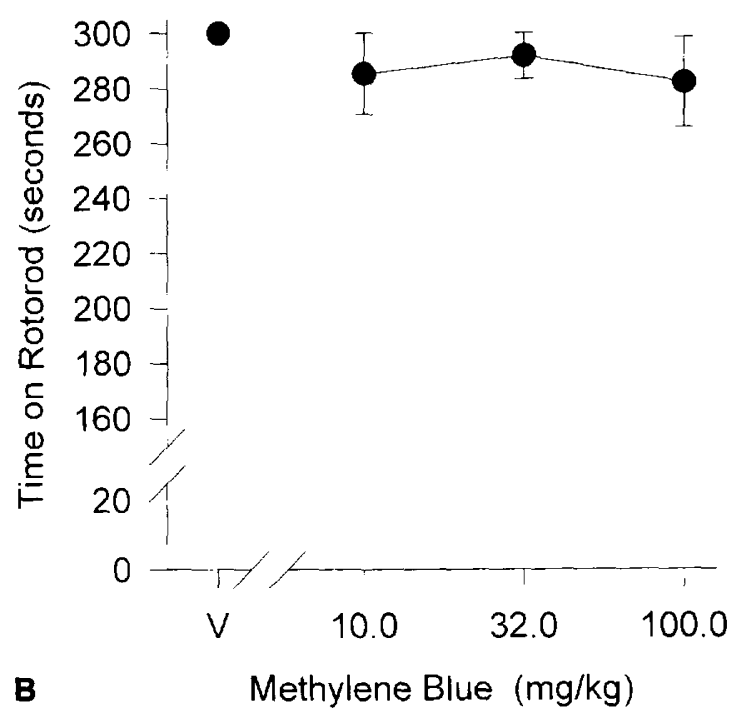

Figure 5. (A) Mean ( \pm SEM) time on the rotorod for groups of mice $(n=15 /$ group) injected with either $100 \mathrm{mg} / \mathrm{kg}$ of 7-nitroindazole (point above 100) or its vehicle (cyclodextrin, point above V). (B) The details are identical to A, with the exception that data are presented for a range of doses of methylene blue.

NO production (or function) could relieve the NMDA receptor complex from the "feedback" inhibition that would result from an oxidized state of $\mathrm{NO}$ binding to the redox modulatory site on the NMDA receptor complex (Lipton et al. 1993a, 1993b). The existence of this redox modulatory site has been proposed to be a mechanism of dampening NMDA-mediated depolarization/ neurotransmission under circumstances of excessive $\mathrm{NO}$ production. It is also possible that the effects of 7-NI and $\mathrm{MB}$ in antagonizing $\mathrm{MK}-801$-induced popping behaviors are unrelated to NO-mediated signal transduction. However, given their structural dissimilarity and common actions with respect to NO function, this seems unlikely.

Finally, beneficial effects of MB in the treatment of psychosis and mania were reported by Bodoni almost 100 years ago (Bodoni 1899). Because MB possesses a phenothiazine nucleus and has been postulated to affect electron transfer reactions, it has more recently been tried empirically for the treatment of manic-depressive illness with some limited therapeutic success (Narsapur and Naylor 1983). Moreover, some antipsychotic drugs such as trifluoperazine and fluphenazine are capable of binding and sequestering calmodulin. Drugs capable of sequestering calmodulin have been shown to inhibit NOS activity and decrease NO production (Dawson et al. 1995). However, it is not known whether the ability of certain antipsychotic drugs to bind to calmodulin (and consequently decrease NO production) contributes to their antipsychotic profile. Nonetheless, our data suggest that inhibitors of NOS or NO-induced activation of guanylate cyclase may have antipsychotic actions in humans.

\section{REFERENCES}

Akbarian S, Bunney WE, Potkin SG, Wigal SB, Hagman JO, Sandman CA, Jones EG (1993a): Altered distribution of nicotinamide-adenine dinucleotide phosphate-diaphorase cells in frontal lobe of schizophrenics implies disturbances of cortical development. Arch Gen Psychiatry 50:169-177

Akbarian S, Vineula A, Kim JJ, Potkin SG, Bunney WE, Jones EG (1993b): Distorted distribution of nicotinamide-adenine dinucleotide phosphate-diaphorase neurons in temporal lobe of schizophrenics implies anomalous cortical development. Arch Gen Psychiatry 50:178-186

Andreason NC, Arndt S, Swayze II V, Cizaldo T, Flaum M, O'Leary D, Ehrhardt JC, Yuh WTC (1994): Thalamic abnormalities in schizophrenia visualized through magnetic resonance image averaging. Science 266:295-298

Babbedge RC, Bland-Ward PA, Hart SL, Moore PK (1993): Inhibition of rat cerebellar nitric oxide synthase by 7-nitroindazole and related substituted indazoles. Br J Pharmacol $110: 225-228$

Bodoni P (1899): Le bleu de methylene comme calmant chez les alienes. Semaine Med 7:56

Bredt DS, Snyder SH (1992): Nitric oxide, a novel neuronal messenger. Neuron 8:3-11

Das I, Khan NS, Canthaboo M, Puri BK, Sooranna SR, de Belleroche J, Hirsch SR (1995): Circulating L-arginine metabolites and platelet nitric oxide synthase in schizophrenics. Schizophrenia Research 15:55

da Silva SV, da Silva VJ, Ballejo G, Salgado MC, Salgado HC (1994): Blockers of the L-arginine-nitric oxide-cyclic GMP pathway facilitate baroreceptor resetting. Hypertension 23(1 Suppl):I60-I63

Dawson TM, Dawson VL, Snyder SH (1992): A novel neuronal messenger molecule in brain: The free radical, nitric oxide. Ann Neurol 32:297-311 
Dawson TM, Hung K, Dawson VL, Steiner JP, Snyder SH (1995): Neuroprotective effects of gangliosides may involve inhibition of nitric oxide synthase. Ann Neurol 37:115-118

Deutsch SI, Mastropaolo J, Schwartz BL, Rosse RB, Morihisa JM (1989): A "glutamatergic hypothesis" of schizophrenia: Rationale for pharmacotherapy with glycine. Clin Neuropharmacol 12:1-13

Deutsch SI, Hitri A (1993): Measurement of an explosive behavior in the mouse, induced by MK-801, a PCP analogue. Clin Neuropharmacol 16:251-257

Foster AC, Wong EHF (1987): The novel anticonvulsant MK801 binds to the activated state of the N-methyl-D-aspartate receptor in rat brain. $\mathrm{Br} J$ Pharmacol 91:403-409

Ferris RM, Harfenist M, McKenzie GM, Cooper B, Soroko FE, Maxwell RA (1982): BW 234 U, (cis-9-[3-3,5-dimethyl1-piperazinyl) propyl] carbazole dihydrochloride: A novel antipsychotic agent. J Pharm Pharmacol 34:388-390

Iversen LL, Woodruff GN, Kemp JA, Foster AC, Gill R, Wong EHF (1989): Noncompetitive glutamate antagonists: Pharmacology and neuroprotective effects of the NMDA antagonist MK-801. In Barnard EA, Costa E (eds), Allosteric Modulation of Amino Acid Receptors: Therapeutic Implications. New York: Raven, pp 347-356

Javitt DC (1987): Negative symptomatology and the PCP (phencyclidine) model of schizophrenia. Hillside J Clin Psychiatry 9:12-35

Javitt DC, Zukin SR (1991): Recent advances in the phencyclidine model of schizophrenia. Am J Psychiatry 148:13011308

Khan NS, Das I, Puri BK, de Belleroche J, Hirsch SR (1995): Presence of a nitric oxide synthase inhibitor in schizophrenic subjects plasma. Schizophr Res 15:62-63

Karson CN, Garcia-Rill E, Biedermann J, Mrak RE, Husain MM, Skinner RD (1991): The brainstem reticular formation in schizophrenia. Psychiatr Res 40:31-48

Lipton SA (1993a): Prospects for clinically tolerated NMDA antagonists: Open-channel blockers and alternative redox states of nitric oxide. TINS 16:527-532

Lipton S, Choi Y, Pan Z, Lei S, Chen H, Sucher N, Loscalzo J, Singel D, Stamler J (1993): A redox-based mechanism for the neuroprotective and neurodestructive effects of nitric oxide and related nitroso-compounds. Nature 364:626-632
Lorrain D, Hull E (1993): Nitric oxide increases dopamine and serotonin release in the medial preoptic area. Neuropharmacol Neurotox 5:87-89

Martin W, Villani GM, Jothianandan D, Furchgott RF (1985): Selective blockade of endothelium-dependent and glyceryl trinitrate-induced relaxation by hemoglobin and by methylene blue in the rabbit aorta. J Pharmacol Exp Ther 232:708-716

Mayer B, Brunner F, Schmidt K (1993): Novel actions of methylene blue. Eur Heart J 14(Suppl I):22-26

Meltzer HY, Matsubara S, Lee J-C (1989): Classification of typical and atypical antipsychotic drugs on the basis of dopamine $\mathrm{D}_{1}, \mathrm{D}_{2}$, and $5-\mathrm{HT}_{2} \mathrm{pK}_{\mathrm{i}}$ values. J Pharmacol Exp Ther 251(1):238-246

Meltzer HY (1991): The mechanism of action of novel antipsychotic drugs. Schizophr Bull 17:263-287

Moncada S, Higgs A (1993): The L-arginine-nitric oxide pathway. N Engl J Med 329:2002-2012

Moore PK, Wallace P, Gaffen Z, Hart SL, Babbedge RC (1993): Characterization of the novel nitric oxide synthase inhibitor 7 nitro indazole and related indazoles: Antinociceptive and cardiovascular effects. Br J Pharmacol 110:219-224

Murad F (1994) The role of nitric oxide in modulating guanylyl cyclase. Neurotransmissions 10:1-4

Narsapur SL, Naylor GJ (1983): Methylene blue. A possible treatment for manic depressive psychosis. J Affective Disord 5:155-161

Rosse RB, Mastropaolo J, Koetzner L, Morn CB, Sussman DM, Deutsch SI (1995): Computerized measurement of MK-801-elicited hyperactivity and popping in mice. Clin Neuropharmacol 18:448-457

Schmidt WJ (1991): The glutamatergic system as a target of antipsychotic drug action. In Oliver B, Mos J, Slangen JL (eds), Animal Models in Psychopharmacology. Boston, Birkhauser Verlag, pp 289-293

Snyder SH, Bredt DS (1992): Biological roles of nitric oxide. Sci Am 266:68-77

Tsou K, Snyder GL, Greengard P (1993): Nitric oxide/CGMP pathway stimulates phosphorylation of DARPP-32, a dopamine- and CAMP-regulated phosphoprotein, in the substantia nigra. Proc Natl Acad Sci USA 90:3462-3465 